\title{
Research on China and the US Service Trade Structures Based on Technical Value Added
}

\author{
Xinying Liu, Xiawei Shen \\ School of International Economics and Trade, Shandong University of Finance and Economics, Jinan, China \\ Email: sheila_guo1988@hotmail.com, shenxiawei@163.com
}

Received May 2014

\begin{abstract}
China and the United States have been important partners in service trade. Much research has been done on the traditional indexes which reflect the two countries' service trade structure, indicating that technology is playing an increasingly significant role in international trade. We use a new index of technical value added to analyze the service trade structure of the two countries. As a result, we can calculate tradable technical value added based on the Technical Value Added theory. We also introduce the method to calculate and measure the service trade's category according to the classification of the International Trade Center in China and the US. Finally we figure out the structures of the service trade in both countries as well as some proposals to optimize the structure.
\end{abstract}

\section{Keywords}

\section{Trade, Technical Value Added, Trade Structure}

\section{Introduction}

We tend to do research on one country's trade structure to know its development status in some industry because a country's foreign trade structure can reflect its economic development level, industrial structure and technological development level [1]. As technology plays an important role in international trade, analyzing trade structure with products' technical value added has been a new trend and this analysis can reflect both sides' position in their trade and their strengths and weakness intuitively [2].

We can also try to use this way to do some research on service trade between China and the United States. Besides, in our opinion, China is a developing country and it depends on exporting labor extensive products which have little technique in them on the world market. There is a big gap between China and the US in exporting, including service trade. However, in these years, after rapidly developing, China has made a big progress in international trade, especially in service trade, and it seems that our service trade structure has improved a lot and China is trying its best to catch the US. But what is the truth? The following analysis by the index of products' technical value added may be helpful.

\section{Outline on Technical Value Added}

Advanced production equipment and manufacturing process cannot make a high-tech product, but the contribu- 
tion technology makes in the process of producing. Products' technical value added (TVA) is the increase of products' added value due to the use of technology.

The TVA principle is: for a product, if the country which is good at producing it is plentiful in technology, there will be more technology used during the producing process and the products it produces will be high technical value added [3]. We assume that the product which comes from rich country is high value added, we regard weighted average of exporters' GDP per capita as products' technical value added, and the weight is the proportion export country's export amount in the total export value of the whole world. Researchers always use Log function on GDP per capita as it has exponential distribution to decelerate the fluctuation of the data. We can get:

$$
\mathrm{TVA}_{j}=\sum_{i=1}^{n} w_{i j} \ln \left(Y_{i}\right)
$$

In this formula, TVA ${ }_{j}$ is the technical value added of product $j, Y_{i}$ is the GDP per capita of country $i$, $n$ is the number of countries on the world market, $w_{i j}$ is the proportion country's export value in the whole world's export amounts on product $j$. And

$$
w_{i j}=X_{i j} / \sum_{i=1}^{n} X_{i j}
$$

We can know that if we want to get a product's TVA we must get every export country's export value on this product on the world market, the whole export amount on this product, and every country's GDP per capita [4]. In economics, technology always means the total factors productivity so we often use the total factors productivity to measure if a country is plentiful in technology. In other words, if the country's total factors productivity is very big; we always think that its technology is ample. However, it is nearly impossible to calculate all the countries' total factors productivity, so a feasible method is to use the labor productivity instead. If we ignore the difference of population structure we can use the index of GDP per capita to measure the labor productivity. After we get every product's TVA, we can arrange them on the horizontal axis in order from small to large, and the vertical axis means the export amount of the product in the country, then we can analyze the country's trade structure by this chart. What we must say is the index of TVA itself is not meaningful but the order; we do not use the data of all the products' TVA but arrange them from small to large. From the order and their corresponding export value we can get the trade structure.

Figure 1 is an example of products' technical value added distribution. In the chart, the horizontal axis is the different products with different TVA arranged in order from small to large, and if the vertical axis is a country's export value (EV), the chart is the chart of products' export technical value added distribution, if the vertical axis is a country's import value (MV), the chart turns to the chart of products' import technical value added distribution. If Figure 1 is assumed as the products' export technical value added distribution of country A and country B, the curve A and curve B are the two countries' technical value added distribution curves. The intersecting part means that the two countries both export these products, and they are competitive in this product's exporting on the international market. The bigger the size of intersecting parts, the competition between the two countries is fiercer.

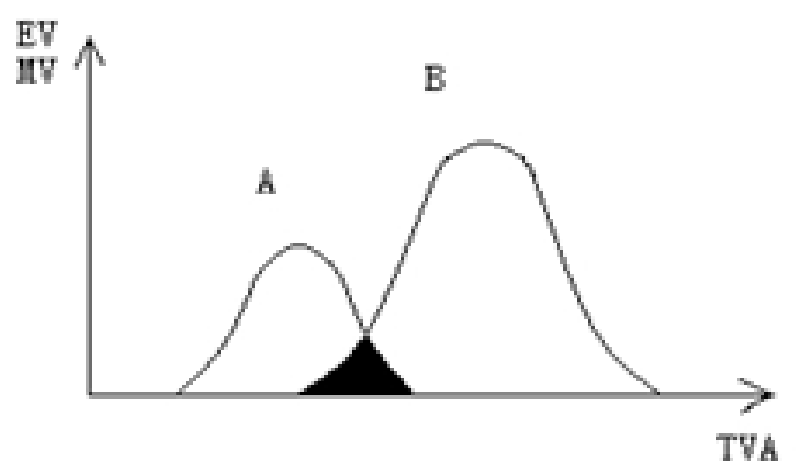

Figure 1. Technical value added distribution. 


\section{Analysis on China and the US Service Trade TVA}

The data here has been classified to analyze service trade structure of China and the US [5]. Different institutions have different classifications of service trade in the world and we select the category been classified by International Trade Center. Compared to other classifications, International Trade Center classify service trade into eleven categories and they are: communication service, travel service, transportation service, construction service, computer and information service, government service, insurance service, personal, culture and entertainment service, financial service, royalties and license service and other commercial service. We select the data in 2006 and 2011 to compare and analyses to get the service trade structure of China and the US, and their change during the five years. Table 1 and Table 2 are the data and all the data comes from ITC calculations based on United Nations Statistics Division statistics.

From the above Table 1 and Table 2, to compare the two countries horizontally we can get that all the categories' export value in the United States is bigger than that in China except construction during the eleven categories, and most of the Chinese export value is far less than that in the United States. In 2006, construction service

Table 1. The situation of port logistics in major coastal ports of China.

\begin{tabular}{|c|c|c|c|c|}
\hline & the US & Proportion (\%) & China & Proportion (\%) \\
\hline Communication & $7,426,000$ & 0.0176 & 737,870 & 0.0080 \\
\hline Travel & $111,277,000$ & 0.2639 & $33,949,000$ & 0.3690 \\
\hline Transportation & $57,140,000$ & 0.1356 & $21,015,300$ & 0.2285 \\
\hline Construction & $1,856,000$ & 0.0044 & $2,752,640$ & 0.0299 \\
\hline Computer and Information & $10,079,000$ & 0.0239 & $2,957,710$ & 0.0321 \\
\hline Other Commercial Service & $76,026,000$ & 0.1804 & $28,972,500$ & 0.3149 \\
\hline Government Service & $16,421,000$ & 0.0390 & 578,690 & 0.0063 \\
\hline Insurance & $9,445,000$ & 0.0224 & 548,180 & 0.0060 \\
\hline Personal, Culture and Entertainment & 431,000 & 0.0010 & 137,430 & 0.0015 \\
\hline Finance & $47,882,000$ & 0.1136 & 145,430 & 0.0016 \\
\hline Royalties and License & $83,549,000$ & 0.1982 & 204,500 & 0.0022 \\
\hline
\end{tabular}

Source: ITC calculations based on United Nations Statistics Division Statistics.

Table 2. China and the US service trade export value in 2011 (unit: thousand dollars).

\begin{tabular}{ccccccc}
\hline & US & Proportion (\%) & China & Proportion (\%) US Growth Rate (\%) China Growth Rate (\%) \\
\hline Travel & $149,640,000$ & 0.2504 & $48,514,824$ & 0.2650 & 0.2564 & 0.3002 \\
Transportation & $78,928,704$ & 0.1321 & $35,610,928$ & 0.1945 & 0.2761 & 0.4099 \\
Computer and Information & $15,313,200$ & 0.0256 & $12,174,099$ & 0.0665 & 0.3418 & 0.7571 \\
Construction & $2,611,000$ & 0.0044 & $14,794,590$ & 0.0808 & 0.2892 & 0.8139 \\
Communication & $12,988,300$ & 0.0217 & $1,689,328$ & 0.0092 & 0.4283 & 0.5632 \\
Government Service & $18,604,000$ & 0.0311 & 668,241 & 0.0037 & 0.1173 & 0.1341 \\
Personal Culture and & $15,906,090$ & 0.0266 & 146,516 & 0.0008 & 0.9729 & 0.0621 \\
Entertainment Service & $111,397,000$ & 0.1865 & $64,527,736$ & 0.3524 & 0.3175 & 0.5511 \\
Other Commercial Service & $15,351,000$ & 0.0257 & $3,345,888$ & 0.0183 & 0.3847 & 0.8362 \\
Insurance & $103,797,296$ & 0.1737 & 830,484 & 0.0045 & 0.1951 & 0.7538 \\
Finance & $72,989,000$ & 0.1222 & 798,672 & 0.0043 & 0.3439 & 0.8179 \\
\hline Royalties and License & &
\end{tabular}

Source: ITC calculations based on United Nations Statistics Division Statistics. 
export value in China is 2752 million dollars, but in the US is just about 1856 million dollars, and China is nearly 1.5 times bigger than that in the US. In 2011, the data in China is almost six times bigger than that in the US. So what can be get is that China is good at offering construction service and in my opinion the labor cost is quiet cheaper than that in the US may be the main reason. But other ten categories, China cannot compare with the US in total amount. In all, the US has more advantages in service trade than China. After 5 years' development, from 2006 to 2011, the total gap of the export amount between China and the United States is still significantly large.

To compare the data in Table 1 and Table 2 vertically, we can get the advantage and disadvantage products in the US and China in the two years. In 2006 in the US, we can get that travel service accounts most in service trade, and then the royalties and license service, then the other commercial service, transportation service and finance service also accounts a relative big proportion. The other categories' proportion is quiet less than them. In China in 2006, travel service, other commercial service and transportation accounts more than $90 \%$, and all of the other categories account less than $10 \%$. In 2011, in the US nearly all the categories' proportion does not change, but finance service's proportion rises from $11 \%$ to $17 \%$, and royalties and license service's proportion decreases from $19 \%$ to $12 \%$. In China, the change is bigger. The proportion of travel decreases from $37 \%$ to $26 \%$, the proportion of transportation decreases from $23 \%$ to $19 \%$, the other commercial service's proportion rises from $31 \%$ to $35 \%$. Most of the other categories rise.

Then, if we concentrate on the total export amount on Table 2 we can also acknowledge that the data in 2011 of both countries increase a lot compared to the data in 2006. If we focus on the increase rate of the concrete data, however, is not the same, almost all the classifications' increase rate of China is far bigger than that in the United States just except the increase rate of personal, culture and entertainment. The increase rate of personal, culture and entertainment in the US is 0.97 , but China has only 0.06 . Therefore, the US is not so good at offering personal, culture and entertainment but it develops a lot in these years. But in other categories of service trade, compared to the US, China has made a relative bigger progress. So we can get a conclusion that during the 5 years' development, the development pace of service trade in China is more quickly and China has been improving all the time, and just because the United States service trade cardinal number is relatively large, nearly all the data is still quite bigger than that in China [6].

Furthermore, we use the concrete export data in China and the United States service trade in 2006 and 2011 in Table 1 and Table 2 and every export country's service trade data on the world to calculate the TVA of all the categories of service trade by the Formula (1), and then arrange them in order on the horizontal axis from small to large to get Figure 2 and Figure 3 (as other commercial service includes many small kinds of services, we cannot use some specific kind of data to substitute so we do not put this kind of service in the following charts). In 2006, from small to large, the order of the categories is: travel service, transportation service, communication service, construction service, computer and information service, government service, insurance service, personal, culture and entertainment service, finance service and royalties and license service. In 2011, the order is: travel service, transportation service, computer and information service, construction service, communication service, government service, personal, cultural and entertainment service ,insurance service, finance service, royalties and license service. The order in two different years is different but almost the same, so the different categories' TVA does not change greatly in these years.

In Figure 2 and Figure 3, the horizontal axis is the different categories whose TVA is from small to large, but the order is different in 2006 and 2011. As this passage focus on the research on service trade, the span of TVA is limited and the products' TVA is almost similar if the products belong the same value added level (we always divide products into high value added, middle value added and low value added), with data in different years we can get different order. For example, insurance, finance, royalties and license service are all high value added products, if we use data in different years we can get a different order, so it is not necessary to care the specific order of the products in the same TVA level. The vertical axis is China and the United States different categories' export value in 2006 and in 2011. The two curves are China and the United States service trade technical value added distribution.

Figure 2 and Figure 3 looks different from Figure 1 but they are also the TVA distribution figure. As two big trade countries, China and the United States both are important exporters on the international market, especially in service trade, so the two countries export all the categories of service trade and all the categories are intersecting in the figure. According to the above analysis of Figure 1, China and the United States are competitive in all the service trade classification, but we also recognize that if the intersecting part size is big which 


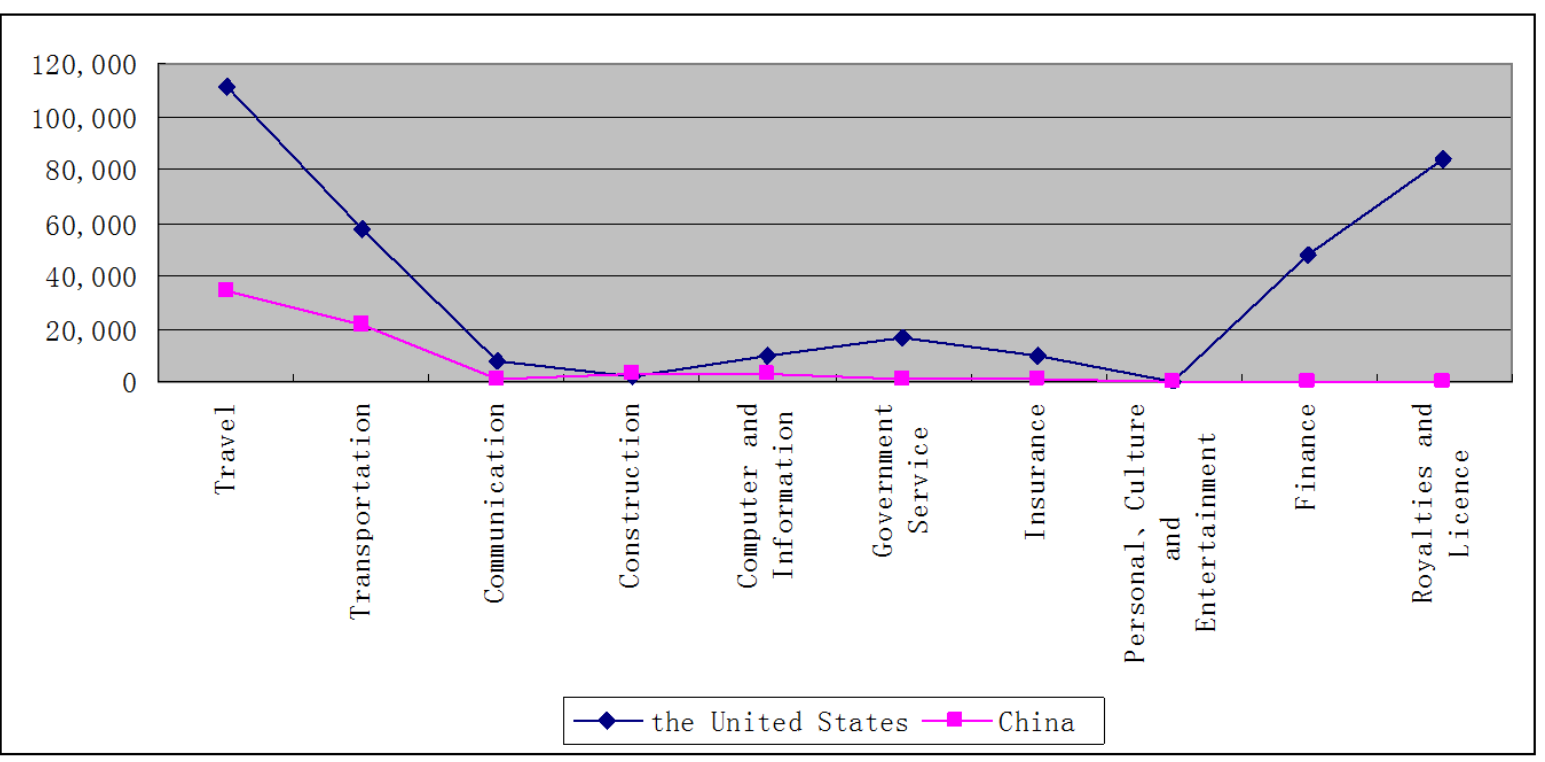

Figure 2. China and the US service trade TVA distribution in 2006. Unit: million dollars Source: ITC calculations based on United Nations Statistics Division statistics

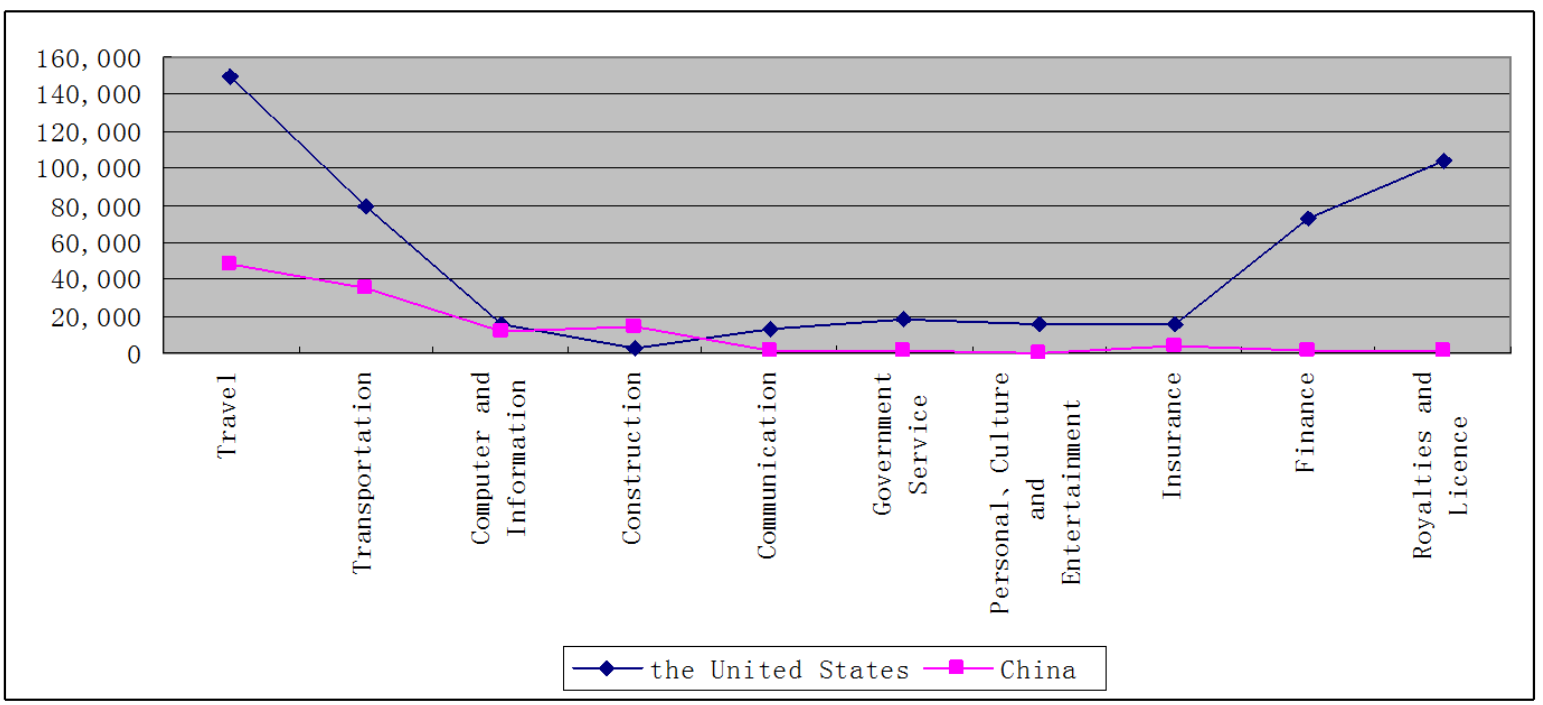

Figure 3. China and the US service trade TVA distribution in 2011 Unit: million dollars Source: ITC calculations based on United Nations Statistics Division statistics.

means their export value of this category is similar, their competitiveness is fierce. On the contrary, if their export value of some category of the service trade is significantly different which means their competitiveness is very small and even they are complementary in this category [7].

From Figure 2 we can get that, except other commercial service, in the year of 2006, the products who's TVA are relative low and high account most of the service trade export in the United States, the products whose TVA are middle are relative few. For instance, travel service and transportation service as a symbol of low technical value added products accounts a lot in the US service trade. And finance service and royalties and license service as a symbol of high value added products also has a heavy export value. But any one of the other categories has a small proportion of the total export amount in the US. In China, except other commercial service, the products whose TVA are relative low account most of service trade, such as travel service and transportation service just like the US. And the other categories of service trade are significantly few. As to the relative high TVA products, the gap between China and the United States service trade export value is very big and the com- 
petitiveness is small, in my opinion, cause China is a developing country and its technical level is far lower than the United States although it is trying its best to improve its economics, so as to the products' quality and it is difficult to compete with the United States in these products exporting on the world market. As to the products whose TVA is relative low which account most of China service trade export value, the United States also export a lot, the intersecting part is very big so the competitiveness between the two countries is fierce.

From Figure 3 we can get that the whole export value of all the categories of service trade in both countries rises up, the development pace in China is faster than that in the United States but the increase amount in the United States is far more than that in China. Except other commercial service, the US export most products whose TVA are relative low and high, the middle TVA products export value also get improved. In China, the low TVA and middle TVA products export value increase sharply and become more separate. Its high TVA products export value also gets raised but still a quiet small amount if it is compared with the United States. Therefore, in 2011, China and the United States are still significantly competitive in low and middle TVA products export and relative less competitive in high TVA products export even complementary. After a few years' development, China still depend on exporting low TVA products in service trade and the two countries' service trade structure does not change very greatly. Moreover, the gap between the two countries' service trade exporting is not become smaller but bigger in all.

\section{Conclusions}

Based on the above analysis what can be concluded is the service trade structure in China and the United States. The service trade structure in the United States is that except other commercial service, the products whose TVA is relative low and high accounts most and the middle TVA products export accounts less. What is in China is, compared to the United States, total export amount is less and China exports mostly low TVA products, high TVA products are few. But in fact China has improved in service trade structure although it is not quite obvious. Furthermore, the two countries' total service trade amount is increasing all the time but high TVA products export value in China is still very few.

After analyzing the service trade structure in China and the United States, we can acknowledge that the two countries compete fiercely on low and middle TVA products' export and they both have advantage in producing them. As to the high TVA products, China cannot compete with the United States and even be complement. China must take this status into consideration and take great efforts to develop low and middle TVA products which are its advantaged products. Meanwhile, China must recognize its disadvantaged products which are high TVA products and invest more, tighten government macro-control, offer more support to high TVA products' development, learn from others' advantages and close the gap, cooperate more with the United States on their complementary products to make progress together.

\section{References}

[1] Baldwin, R.E. (1971) Determinants of the Commodity Structure of U.S. Trade. American Economic Review, 61, 126146.

[2] Grossman, G.M. and Helpman, E. (1995) Technology and Trade. In: Grossman, G.M. and Rogoff, Eds., Handbook of International Economics, Vol. 3, North Holland, Amsterdam.

[3] Davis, Weinstein, Bradford and Shimpo, (1997) Using International and Japanese Regional Data t Determine when the Factor Abundance Theory of Trade Works. American Economic Review, 87, 421-446.

[4] Guan, Z.X. (2006) Analyzing the Foreign Trade Structure Based in Technologies of Trade Goods. International Economic Review No. 4-5.

[5] Lall, S. (2000) The Technological Structure and Performance of Developing Country Manufactured Exports1985-1988. QEH Working Paper Series-WEHWPS44, June 2000.

[6] Hausmann, R., Hwang, H. and Rodrik, D. (2007) What You Export Matters? Economic Growth, 12, 1-25.

[7] Lall, S. and Albaladejo, M. (2004) China’s Competitive Performance: A Threat to East Asian Manufactured Exports? World Development, 32, 1441-1446. http://dx.doi.org/10.1016/j.worlddev.2004.03.006 